\title{
Effects of vegetation types on soil water dynamics during vegetation restoration in the Mu Us Sandy Land, northwestern China
}

\author{
Yu Xiaona ${ }^{1}$, Huang Yongmei $^{2 *}$, Li Engui ${ }^{2}$, Li Xiaoyan $^{2}$, Guo Weihua $^{1}$ \\ ${ }^{1}$ Institute of Ecology and Biodiversity, College of Life Science, Shandong University, Jinan 250100, China; \\ ${ }^{2}$ College of Resources Science and Technology, Beijing Normal University, Beijing 100875, China
}

\begin{abstract}
The arid and semi-arid northwestern China has been undergoing ecological degradation and the efforts to reverse the ecological degradation have been undertaken for many years. Some shifting dunes have been fixed and the vegetation has been partially recovered in certain areas and the Mu Us Sandy Land in the Ordos Plateau is an example of the success. The present study attempts to reveal the relationships between the vegetation restoration and ecohydrology in the $\mathrm{Mu}$ Us Sandy Land. We continuously measured soil water content at 10-min intervals under three vegetation types (i.e., shifting dune, shrub-dominated community, and herb-dominated community) in the Mu Us Sandy Land from April 2012 to October 2013. The results show the infiltration coefficient increased with increased rainfall amount and eventually reached a stable value. Infiltration coefficients were $0.91,0.64$, and 0.74 in the shifting dune, in the shrub-dominated community, and in the herb-dominated community, respectively. Cumulative infiltration and soil texture are two vital factors affecting the depths of rainfall penetration. Only rainfall events larger than $35.0 \mathrm{~mm}$ could recharge soil water at the $60-80 \mathrm{~cm}$ layer in the herb-dominated community. Our results imply that the expected forward succession of restored vegetation may be destined to deterioration after reaching the climax simply because of following two facts: (1) soil water is mainly retained at shallower layer and (2) plant fine roots mainly distribute in deeper layer in the herb-dominated community.
\end{abstract}

Keywords: ecohydrology; soil water content; vegetation restoration; Artemisia ordosica community

Citation: Yu Xiaona, Huang Yongmei, Li Engui, Li Xiaoyan, Guo Weihua. 2017. Effects of vegetation types on soil water dynamics during vegetation restoration in the Mu Us Sandy Land, northwestern China. Journal of Arid Land, 9(2): 188-199. doi: $10.1007 / \mathrm{s} 40333-017-0054-\mathrm{y}$

\section{Introduction}

Ecological degradation has been recently occurring in many arid and semi-arid areas worldwide (Yang et al., 2005) and the degradation affects approximately $20 \%$ of the world population (Millennium Ecosystem Assessment, 2005; Liu et al., 2014). The arid and semi-arid northwestern China has been recently undergoing ecological degradation and the associated desertification at an alarming rate. However, the efforts to reverse the ecological degradation and the associated desertification have been undertaken since the 1950s, and some shifting dunes have been fixed and the vegetation has been recovered in certain areas (Liu et al., 2014). The Mu Us Sandy Land in the Ordos Plateau is such an example of the success (Wang et al., 2004). Nevertheless, the

*Corresponding author: Huang Yongmei (E-mail: ymhuang@bnu.edu.cn)

Received 2016-05-24; revised 2016-12-29; accepted 2017-01-07

(C) Xinjiang Institute of Ecology and Geography, Chinese Academy of Sciences, Science Press and Springer-Verlag Berlin Heidelberg 2017 
success in restoring vegetation in arid and semi-arid areas has long been ecohydrologically watched (Cheng et al., 2006; Wang et al., 2012).

In terms of ecohydrological researches relevant to vegetation restoration in ecologically degraded lands, many studies predicted that positive feedback mechanisms might have been involved in the ecosystem shifts (van de Koppel et al., 1997, 2002, 2004; Rietkerk and van de Koppel, 1997; Hillerislambers et al., 2001; Castellano and Valone, 2007). The positive feedback mechanisms were linked to several distinctive factors: favorable changes in soil water hydrology (e.g., increased canopy interception and soil infiltration) (Rietkerk and van de Koppel, 1997; van de Koppel, 1997; Hillerislambers et al., 2001); favorable changes in soil properties (e.g., reduced soil compaction, increased soil organic matter, and soil fertility); and favorable changes in soil biological properties (e.g., increased enzyme activities) (Su et al., 2005; Castellano and Valone, 2007; Li et al., 2007; Jeddi and Chaieb, 2010; Zhang et al., 2013).

Among those factors, soil hydrology is the most important in modulating and even controlling various ecohydrological processes in arid and semi-arid areas where the limited rainfall is the major source of soil water replenishment (Cheng et al., 2006) and the importance has been sufficiently illustrated in many reports (e.g., Wang et al., 1997; Guo, 2000; Li et al., 2004; Zhang et al., 2012; Li et al., 2013). The present study focuses on the Mu Us Sandy Land where some of shifting dunes have been fixed and the vegetation has been partially recovered. In fact, some researches on the ecohydrological responses to the vegetation restoration have been conducted in the Mu Us Sandy Land and in the neighboring Tengger Desert. For example, Li (2005) evaluated the ecohydrological outcomes of sand fixing and vegetation restoration and found that vegetation recovery and the associated transition were strongly influenced by the spatial redistribution of soil water. The spatial redistribution was mainly resulted from rainfall-intercepting processes by shrub canopies and soil-infiltrating processes under shrub canopies (Li et al., 2004; Wang et al., 2007, 2013). The present study attempts to further reveal the relationships between the vegetation restoration and ecohydrological processes based on the examples of the succession of sand-binding vegetation in the Mu Us Sandy Land.

\section{Materials and methods}

\subsection{Study area}

The study was carried out at Ordos Sandy Land Ecological Station $\left(39^{\circ} 29^{\prime} 37^{\prime \prime} \mathrm{N}, 110^{\circ} 11^{\prime} 29^{\prime \prime} \mathrm{E}\right.$; Fig. 1) of the Institute of Botany of the Chinese Academy of Sciences. The study site is situated in the northeastern part of the $\mathrm{Mu}$ Us Sandy Land. The annual mean temperature is approximately $6.0^{\circ} \mathrm{C}-8.5^{\circ} \mathrm{C}$, with mean monthly temperatures ranging from $-9.5^{\circ} \mathrm{C}$ to $-12.0^{\circ} \mathrm{C}$ in January and from $22.0^{\circ} \mathrm{C}$ to $24.0^{\circ} \mathrm{C}$ in July. The mean annual precipitation is approximately $350.0 \mathrm{~mm}$ with $60 \%-70 \%$ occurring in the period from July to September.

The typical plant is Artemisia ordosica Krasch., a deciduous subshrub, and it commonly occurs on sand dunes (fixed and shifting) in this area (Zhang, 1994). An autogenic successional pathway in vegetation patterns is associated with the development from shrub-dominated community to herb-dominated community (Wang et al., 1997; Guo, 2000). This succession began with bare-sand dunes, succeeded with semi-fixed sand dunes dominated by $A$. Ordosica and finished with fixed sand dunes also dominated by $A$. ordosica. It then shifted to an $A$. ordosica+moss community on fixed-sand dunes and reached the climax stage characterized by A. ordosica + Stipa bungeana Trin. community (Zhang, 1994). Accordingly, three typical communities in the Mu Us Sandy Land were selected for the field measurements (Fig. 2): shifting dune (no vegetation); shrub-dominated $A$. ordosica community on semi-fixed-sand dune; and herb-dominated $A$. ordosica $+S$. bungeana on the fixed-sand dune.

\subsection{Experimental design and data collection}

Community characteristics and plant aboveground biomass of the three sites were investigated in August 2012. Three $5 \mathrm{~m} \times 5 \mathrm{~m}$ plots were used to study the shrub community characteristics, and three $1 \mathrm{~m} \times 1 \mathrm{~m}$ quadrats were arranged in the center of each shrub plot for plant surveys. 
Belowground biomass was investigated in 2013 at three trenches $(1 \mathrm{~m} \times 1 \mathrm{~m})$ of $80 \mathrm{~cm}$ deep at $10-\mathrm{cm}$ intervals. Biomasses of grass roots, $<2 \mathrm{~mm}$ (fine root) shrub roots, and $>2 \mathrm{~mm}$ (coarse root) shrub roots were separately determined and living roots were separated from dead roots via visual inspection. Soil samples were collected from the three trenches at $10-\mathrm{cm}$ intervals. The collected soil samples were first air-dried and then sieved through a 2-mm screen for physical and chemical analysis. Particle size composition was determined via the hydrometer method (Liu, 1996) and soil organic matter was determined via the $\mathrm{K}_{2} \mathrm{Cr}_{2} \mathrm{O}_{7}-\mathrm{H}_{2} \mathrm{SO}_{4}$ oxidation method of Walkley and Black (1934).

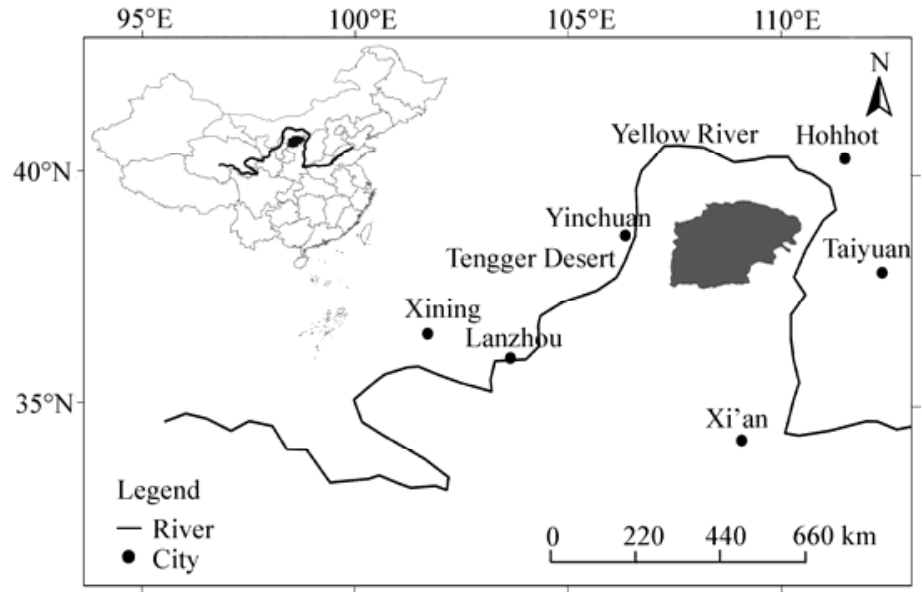

Fig. 1 Location of the Mu Us Sandy Land
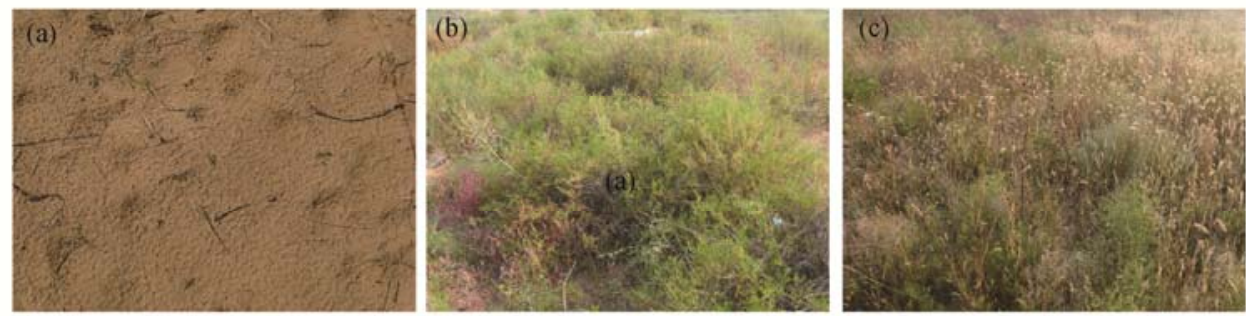

Fig. 2 Landscape of shifting dune (a), shrub-dominated community (b) and herb-dominated community (c)

At each site, $\mathrm{ECH}_{2} \mathrm{O}$ EC-5 (Decagon Devices, Pullman, Washington, USA) probes were installed at $5,15,30,50$, and $70 \mathrm{~cm}$ below the ground to automatically measure the volumetric soil water content (\%) and these probes corresponded to the $0-10,10-20,20-40,40-60$, and 60-80 cm layers. Soil water content data were calibrated according to the empirical calibration equation to attain approximately $\pm(1 \%-2 \%)$ accuracy (Cobos and Chambers, 2010). The rainfall amount in each rainfall event was measured at 10-min intervals with a tipping bucket rain gauge (Model TE 525) (note: rainfall data from 20 July to 26 July were missed due to sensor malfunctioning). Soil water data were used to estimate the average cumulative infiltration. The cumulative infiltration was calculated using the following equation:

$$
W=\sum_{i=1}\left(\theta_{e i}-\theta_{i}\right) \times k
$$

Where $W$ is cumulative infiltration $(\mathrm{mm}) ; \theta_{e i}$ is volumetric soil water content (\%) of layer $i$ (2 hours after each rainfall event); $\theta_{i}$ is initial soil water content in layer $i(\%) ; k$ is thickness of layer $i(\mathrm{~mm})$. Infiltration coefficient $(\alpha)$ was calculated using the following equation:

$$
\alpha=W / R \text {. }
$$

Where $R$ is rainfall amount $(\mathrm{mm})$. Soil water storage was calculated using the following equation: 


$$
D=\sum_{i=1}\left(\theta_{r i} \times k_{i}\right)
$$

Where $D$ is soil water storage $(\mathrm{mm}) ; \theta_{r i}$ is volumetric soil water content in layer $i(\%) ; k_{i}$ is thickness of layer $i(\mathrm{~mm})$. Instant infiltration rate was calculated using the following equation:

$$
I R=\Delta D_{t} / t \text {. }
$$

Where $I R$ is instant infiltration rate $(\mathrm{mm} / \mathrm{min})$ and $\Delta D_{t}$ is increment of soil water storage $(\mathrm{mm})$ within the time of $t(\mathrm{~min})$ during a rainfall event. Based on the increments of volumetric soil water content in soil profile $(0-80 \mathrm{~cm})$ for the three sites, isograms were made using Kriging interpolation. Instant infiltration rate was expressed by slope of soil water storage versus time when the soil water storage was increased with time.

\subsection{Data analysis}

Differences in measured parameters between different samples were analyzed using one-way analysis of variance (ANOVA) and Fisher's protected least significant difference (LSD). ANCOVA was used to test whether the relationship between cumulative infiltration (dependent variable) and rainfall (covariate variable) differed significantly between sites. All statistical analyses were conducted using version 19.0 of the SPSS software (SPSS Inc. Chicago, IL, USA) at the $P=0.05$ level of confidence. Graphic plotting, slope, and derivative of curves were generated with Origin 9.2 (Origin Lab, Northampton, MA, USA) and Surfer 10.0 (Golden Software, Golden, Colorado, USA) software.

\section{Results}

\subsection{Vegetation and soil}

Again, the measurements were conducted at three sites: shifting dune (no vegetation), shrub-dominated community, and herb-dominated community (see Fig. 2). Plants species and biomass were significantly different between the shrub-dominated community and herb-dominated community (Table 1) and the plant cover of the shrub-dominated community $(\sim 40 \%)$ is lower than that of the herb-dominated community $(\sim 60 \%)$. The herb layer of the shrub-dominated community was mainly composed of such annual plants as Euphorbia humifusa, Corispermum candelabrum, Setaria viridis, and Hedysarum leave. The herb-dominated community contained such annual plants as Setaria viridis, Corispermum candelabrum, Bassia dasyphylla, as well as such perennial plants as S. bungeana, Poa sphondylodes, Astragalus melilotoides, and Stellaria filicaulis. The herb species diversity was higher in the herb-dominated community than that in the shrub-dominated community. Obviously, the herb biomass in the herb-dominated community was also significantly higher than that in the shrub-dominated

\begin{tabular}{|c|c|c|c|}
\hline & \multicolumn{3}{|c|}{ Site } \\
\hline & Shifting dune & Shrub-dominated community & Herb-dominated community \\
\hline Artemisia ordosica coverage (\%) & & $32.25 \pm 1.61^{\mathrm{a}}$ & $3.62 \pm 0.18^{\mathrm{b}}$ \\
\hline Community coverage $(\%)$ & & $42.79 \pm 2.14^{\mathrm{b}}$ & $64.44 \pm 3.22^{\mathrm{a}}$ \\
\hline A. ordosica leaf biomass $\left(\mathrm{g} / \mathrm{m}^{2}\right)$ & & $17.58 \pm 0.88^{\mathrm{a}}$ & $3.21 \pm 0.16^{\mathrm{b}}$ \\
\hline Grass biomass $\left(\mathrm{g} / \mathrm{m}^{2}\right)$ & & $14.23 \pm 0.71^{\mathrm{b}}$ & $61.26 \pm 3.06^{\mathrm{a}}$ \\
\hline Soil organic matter content $(\%)$ & $1.80 \pm 0.09^{\mathrm{b}}$ & $1.81 \pm 0.09^{\mathrm{b}}$ & $6.83 \pm 0.34^{\mathrm{a}}$ \\
\hline Sand $(\%)$ & $95.62 \pm 4.78$ & $95.62 \pm 4.78$ & $85.62 \pm 4.28$ \\
\hline Silt $(\%)$ & $2.00 \pm 0.10$ & $2.00 \pm 0.10$ & $8.50 \pm 0.43$ \\
\hline Clay $(\%)$ & $2.38 \pm 0.12$ & $2.38 \pm 0.12$ & $3.88 \pm 0.19$ \\
\hline Dominant species & & $\begin{array}{l}\text { A. ordosica; Hedysarum leave; } \\
\text { Euphorbia humifusa; Corispermum } \\
\text { candelabrum; Setaria viridis }\end{array}$ & $\begin{array}{l}\text { A. ordosica; } \text { H. leave; Stipa } \\
\text { bungeana; Incarvillea } \\
\text { sinensis; Heteropappus } \\
\text { altaicus }\end{array}$ \\
\hline
\end{tabular}

Table 1 Characteristics of communities under different cover types

Note: Values followed by different lowercase letters in the same row indicate significant differences $(P<0.05)$. Soil organic matter content of each site is the average value for $0-20 \mathrm{~cm}$ soil layer. Soil texture (i.e., sand, silt, and clay) in the shifting dune is the same with that in the shrub-dominated community. Mean \pm SE. 
community $(P=0.009)$. However, the leaf biomass of $A$. ordosica was larger $(P=0.000)$ in the shrub-dominated community than that in the herb-dominated community. Soil texture and organic matter content were also significantly different among the stages of succession (i.e., among the three sites). There were no obvious differences between the shifting dune and shrub-dominated community, but clay and silt contents and organic matter content in the herb-dominated community were significantly higher than those in the shrub-dominated community.

The vertical distribution patterns of fine root biomass in the shrub-dominated community were also significantly different from those in the herb-dominated community (Fig. 3). Herb roots mainly distributed in the range of $0-40 \mathrm{~cm}$ depth in the shrub-dominated community and the range spanned from 0 to $80 \mathrm{~cm}$ depth in the herb-dominated community. In shallower layers $(0-20 \mathrm{~cm})$, herb root biomass of the herb-dominated community was 7 times higher than that of the shrub-dominated community. In addition, $\sim 75 \%$ of shrub fine roots distributed in the $0-40 \mathrm{~cm}$ depth in the shrub-dominated community, but only $\sim 40 \%$ of shrub fine roots distributed in the $0-40 \mathrm{~cm}$ depth in the herb-dominated community.

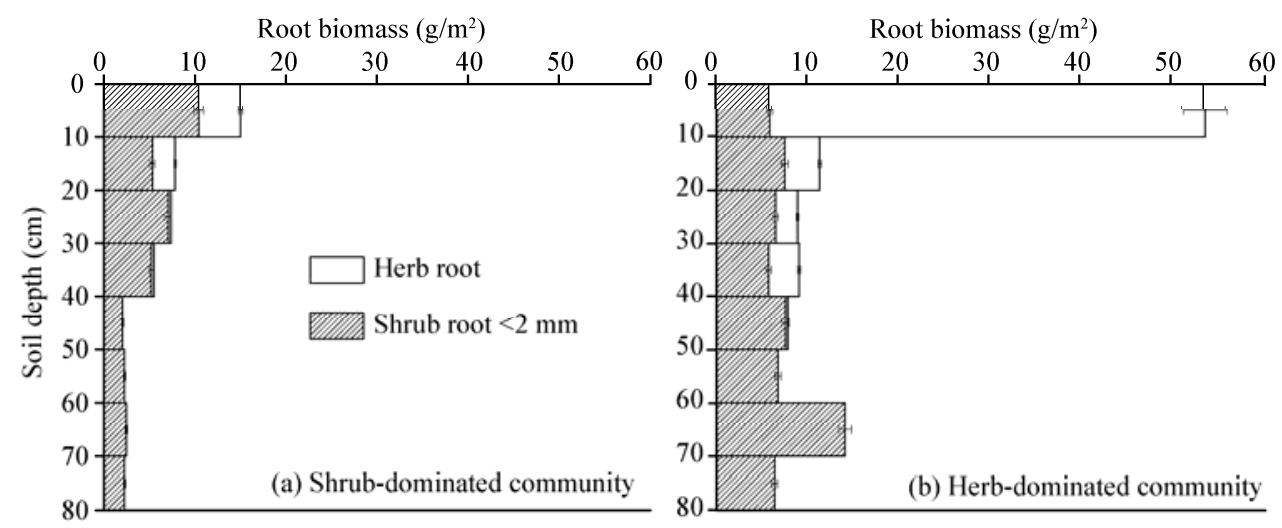

Fig. 3 Vertical distribution of fine root biomass in the shrub-dominated community (a) and the herb-dominated community (b). Bars indicate standard errors.

\subsection{Soil water dynamics}

In general, the diurnal soil water content closely reflected the rainfall patterns (Li et al., 2013). To avoid measurement errors resulted from ice and snow, we collected daily soil water content data only in the growing season (from 1 April to 31 October) in 2012 to evaluate soil water dynamics. Total 68 rainfall events were recorded during the observation period. Approximately, 52\% of rainfall events had the amount of less than $5.0 \mathrm{~mm}, 34 \%$ between 5.0 and $20.0 \mathrm{~mm}$, and $14 \%$ more than $20.0 \mathrm{~mm}$. The most intensive rainfall event (146.0 mm) occurred on 21 July (2012).

As shown in Figure 4, the diurnal soil water content at the $0-60 \mathrm{~cm}$ depth was higher in the herb-dominated community than in the shrub-dominated community during the observation period; while the diurnal soil water content at $60-80 \mathrm{~cm}$ depth was higher in the shrub-dominated community than in the herb-dominated community during the same period. The main fluctuations in the diurnal soil water content were tightly related with the intense rainfall events $(>10.0 \mathrm{~mm})$. The fluctuations were expectedly the largest during and after those extremely intense rainfall events, such as ones on following days: 23 June $(21.4 \mathrm{~mm}), 27$ June $(26.4 \mathrm{~mm}), 21$ July (146.0 $\mathrm{mm}), 26$ August $(32.6 \mathrm{~mm}), 1$ September $(34.8 \mathrm{~mm})$, and 24 September $(29.2 \mathrm{~mm})$. In addition, the soil water content was more sensitive to rainfall in the upper soil layer $(0-20 \mathrm{~cm})$ than in the deeper soil layer $(20-80 \mathrm{~cm})$ under "normal" rainfall events (i.e., less intense or/and less prolonged ones). However, the soil water contents both in the shallower soil layer $(0-20 \mathrm{~cm})$ and in the deeper soil layer $(20-80 \mathrm{~cm})$ were sensitive to rainfall under "abnormal" rainfall events (i.e., extremely intense or/and prolonged ones).

\subsection{Infiltration processes}

Figure 5 shows that there are positive linear correlations between the rainfall amounts during the 

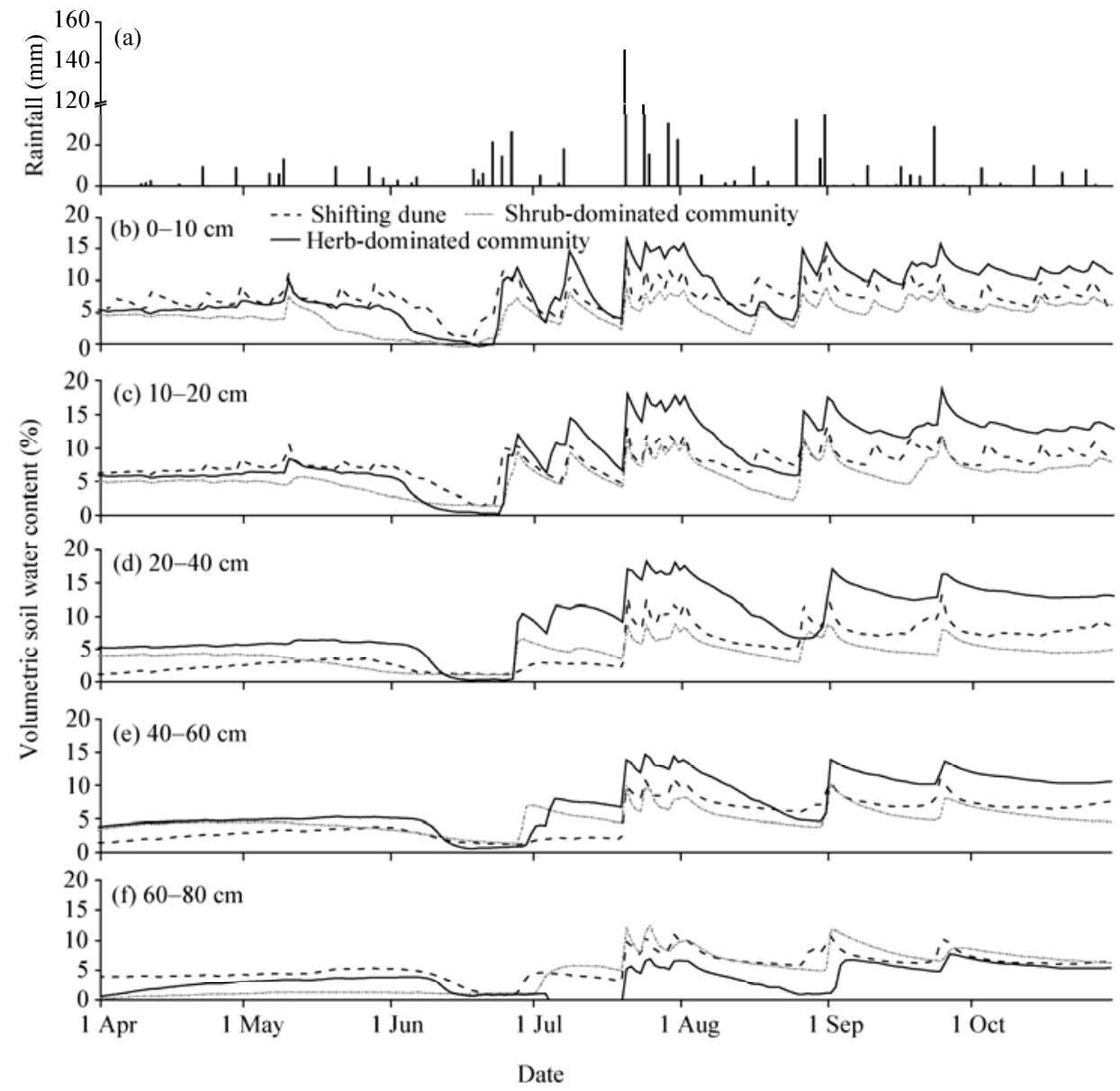

Fig. 4 Daily time series of rainfall (a) and volumetric soil water content in the shifting dune site, shrub-dominated community, and herb-dominated community at soil depths of 0-10 (b), 10-20 (c), 20-40 (d), 40-60 (e), and 60-80 (f) cm. Rainfall data from 20 July to 26 July were missed for the sensor damage.

17 individual rainfall events (each with 5.0-35.0 $\mathrm{mm}$ rainfall) and the corresponding cumulative infiltrations. As shown in Figure 5, the dependency of the cumulative infiltrations on the rainfall amounts was significantly stronger in the shifting dune (no vegetation) than in other two sites (shrub-dominated community and herb-dominated community) and the infiltration initiated more readily under "less-intense" rainfall conditions in the shifting dune. However, the differences between the shrub-dominated community and the herb-dominated community were not significant at all. It should be further noted that during the 17 individual rainfall events (each with 5.0-35.0 $\mathrm{mm}$ rainfall), the total rainfall amount was $253.2 \mathrm{~mm}$. The corresponding cumulative infiltration amount was $220.1 \mathrm{~mm}$ in the shifting dune, $104.0 \mathrm{~mm}$ in the shrub-dominated community, and $115.8 \mathrm{~mm}$ in the herb-dominated community. Infiltration coefficient was the ratio of the cumulative infiltration to the rainfall. The ratio normally increases with the increasing rainfall amount and eventually reaches a stable value. When the rainfall amount of an individual rainfall event was less than $35.0 \mathrm{~mm}$, the largest infiltration coefficient was $0.91,0.56$, and 0.63 in the shifting dune, in the shrub-dominated community, and in the herb-dominated community, respectively. Correspondingly, the stable infiltration coefficient was $0.91,0.64$, and 0.74 .

To unveil the relationships between the soil water content and the rainfall amounts under different vegetation types (or sites), we interpolated incremental soil water content in the soil profile $(0-80 \mathrm{~cm})$ based on the data of the 17 selected rainfall events $(5.0-35.0 \mathrm{~mm})$. Three observations can be made from Figure 6. First, soil water content in the shifting dune was rather 


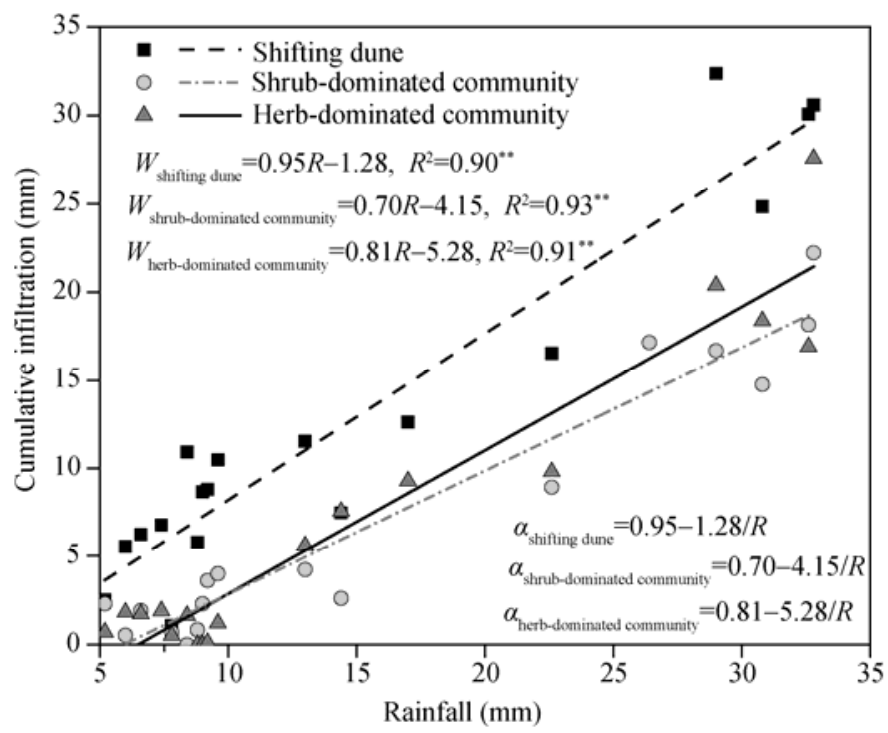

Fig. 5 Response of cumulative infiltration to rainfall based on 17 rainfall events ( $>5.0 \mathrm{~mm}$ ) collected from April to October 2012. Cumulative infiltration was calculated by changes of volumetric soil water content before and after (2 hours) rainfall.

sensitive to rainfall amount. That is, relatively small rainfall events (e.g., $<10.0 \mathrm{~mm}$ ) can readily affect the soil water content in shallower layer (i.e., 0-20 cm) and relatively large rainfall events (e.g., $>25.0 \mathrm{~mm}$ ) can affect the soil water content in deeper layer (e.g., up to $80 \mathrm{~cm}$ ). Second, relatively small rainfall events (e.g., $<10.0 \mathrm{~mm}$ ) can only affect the soil water content in very shallower layer (e.g., $<10 \mathrm{~cm}$ ) under both the shrub-dominated community and the herb-dominated community. Third, even the relatively large rainfall events (e.g., $>30.0 \mathrm{~mm}$ ) cannot penetrate to deeper layer (e.g., $>50 \mathrm{~cm}$ ) under the herb-dominated community.

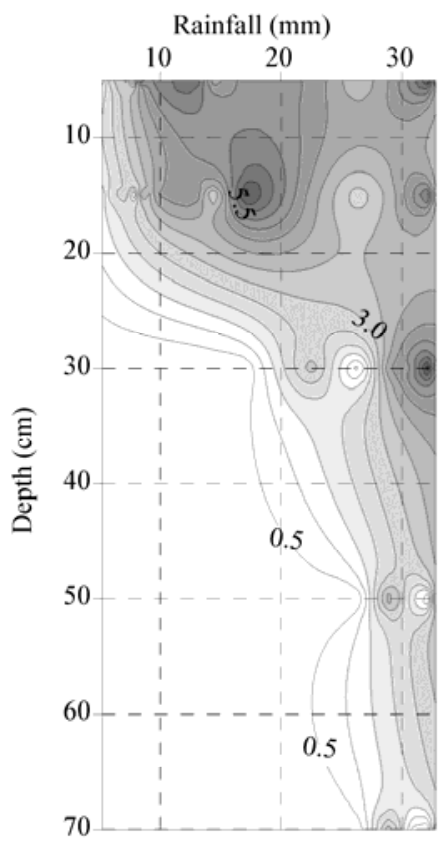

(a) Shifting dune

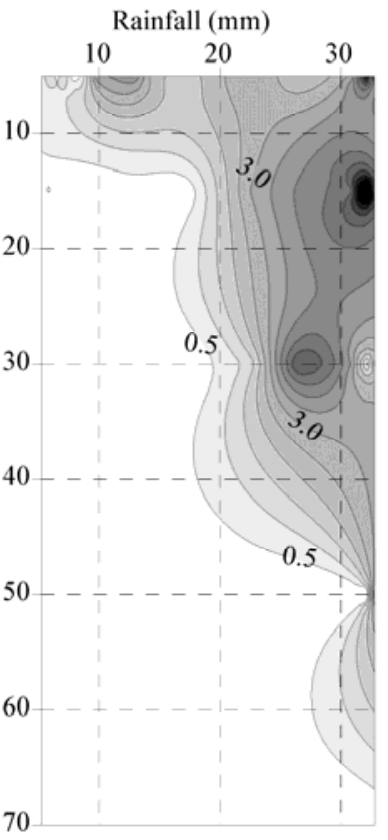

(b) Shrub-dominated community

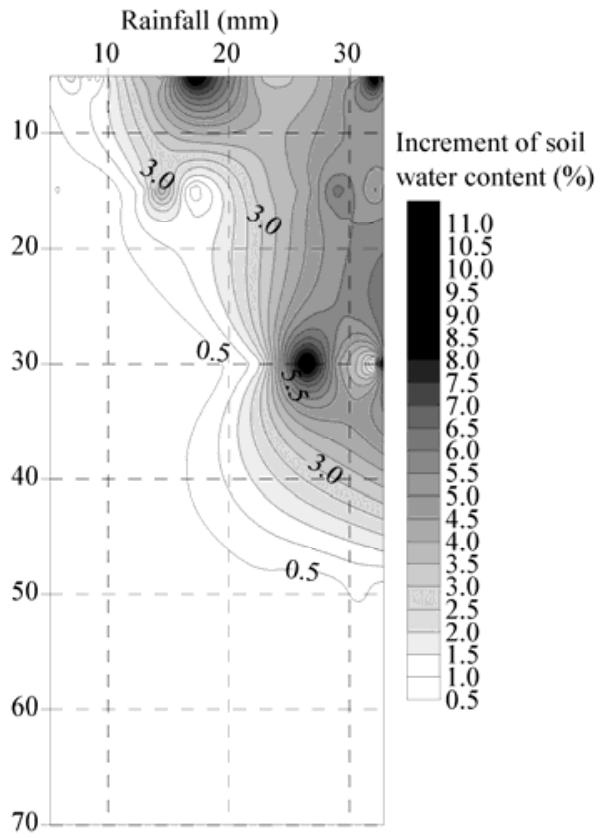

(c) Herb-dominated community

Fig. 6 Isograms based on Kriging interpolation for increments of volumetric soil water content in soil profile $(0-80 \mathrm{~cm})$ for shifting dune (a), shrub-dominated community (b) and herb-dominated community (c) 
To evaluate the responses of soil water storage to the selected rainfall events under different plant communities (or sites), we plotted the total soil water storages in the entire soil layer (0-80 $\mathrm{cm}$ ) versus times in Figure 7. It can be seen that infiltrations both in the shrub-dominated and the herb-dominated communities lag behind that in the shifting dune, further demonstrating the ecohydrological buffering effect of vegetation surfaces (compared with bare surface). It is also apparent that the herb-dominated community had a considerably higher soil water storage than those of other two cases (i.e., shifting sand dune and shrub-dominated community) under any circumstances. To further explore the relationships between rainfall amounts and infiltration rates, we examined five different rainfall events with varying amounts of rainfall: $146.0 \mathrm{~mm}$ (21 July), $68.0 \mathrm{~mm}$ (25 July), $15.4 \mathrm{~mm}$ (26 July), $30.8 \mathrm{~mm}$ (30 July) and $22.6 \mathrm{~mm}$ (1 August). As shown in Figure 8 , the instant infiltration rate was higher in the shifting dune than in other two sites. The highest instant infiltration rate appeared when the rainfall amount was the highest $(146.0 \mathrm{~mm})$. The instant infiltration rate was $1.10 \mathrm{~mm} / \mathrm{min}$ in the shrub-dominated community (lower) and $1.43 \mathrm{~mm} / \mathrm{min}$ in the herb-dominated community (higher) when the rainfall amount was $146.0 \mathrm{~mm}$. However, the instant infiltration rate was higher in the shrub-dominated community than in the herb-dominated community when the rainfall amount was less than $146.0 \mathrm{~mm}$ (e.g., 68.0, 30.8, 22.6 , and $15.4 \mathrm{~mm}$ ). It should be noted that under any circumstances, the instant infiltration was higher in the shifting dune than in other two sites.

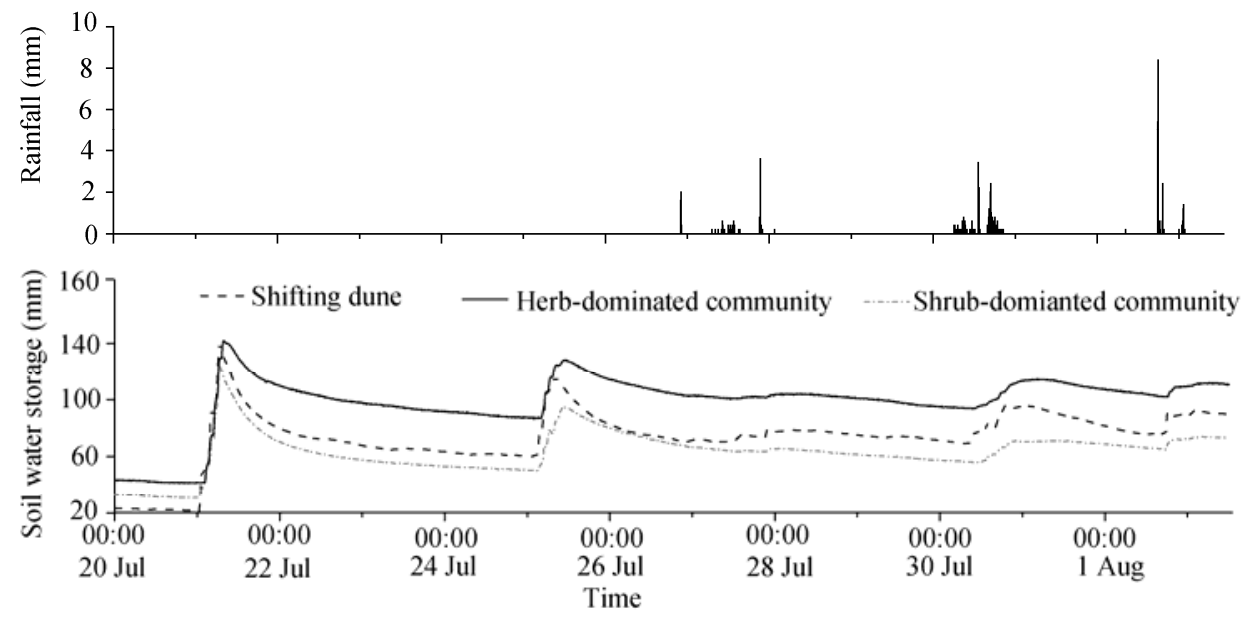

Fig. 7 Ten-minute soil water storage during several rainfall events from 20 July to 1 August at different sites. Rainfall amount was $146.0 \mathrm{~mm}$ on $21 \mathrm{July}, 68.0 \mathrm{~mm}$ on $25 \mathrm{July,} 15.4 \mathrm{~mm}$ on $26 \mathrm{July}, 30.8 \mathrm{~mm}$ on $30 \mathrm{July}$ and $22.6 \mathrm{~mm}$ on 1 August. No data were available for ten-minute rainfall dynamics of 20 July to 26 July due to sensor malfunctioning.

\section{Discussion}

\subsection{Cumulative infiltration}

Infiltration is a physical process that transfers rainfall into soil water in the rhizosphere soil layer (Wang et al., 2007) and vegetation cover and soil texture are the two factors known to affect water infiltration in significant ways (Castellano and Valone, 2007). The rainfall intercepted by plant canopies is primarily evaporated into the atmosphere and thus the soil water recharge was effectively reduced. It was reported that the vegetation canopy interception loss can account for up to $40 \%$ of total rainfall (Liu, 1997; Carlyle-Moses, 2004) and that the average canopy interception loss of $A$. ordosica can account for $26.8 \%$ of the total rainfall (Wang et al., 2004). Our results show that due to no rainfall intercepted by canopies of $A$. ordosica and grasses, the infiltration rate of an individual rainfall in the shifting dune (no vegetation) was significantly higher than those in other two cases (i.e., shrub-dominated community and herb-dominated community). For the same reason, the cumulative infiltration and infiltration coefficient in the 


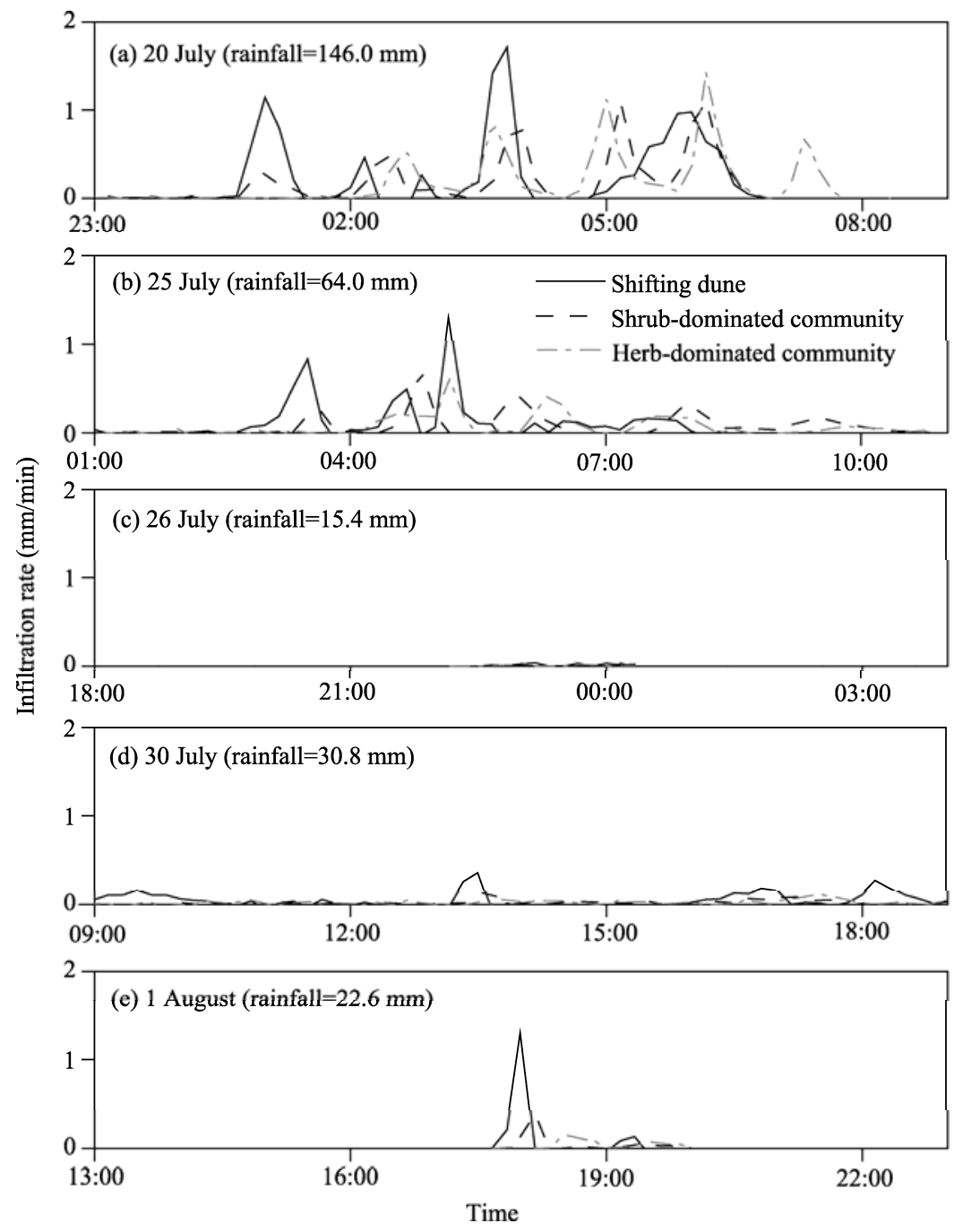

Fig. 8 Instant infiltration rate of rainfall events from 20 July to 1 August

shrub-dominated community and herb-dominated community were significantly lower than those in the shifting dune (Fig. 5). Infiltration rate depends on various factors such as the initial soil moisture and soil texture (Wang et al., 2003; Angelaki et al., 2013). Our results show that infiltration rate in the shrub-dominated community was marginally higher than that in the herb-dominated community when the rainfall amount was moderately high (e.g., 30.8, 22.6, and $15.4 \mathrm{~mm}$; Fig. 7). This may be attributable to higher silt and clay contents in the herb-dominated community and to lower silt and clay contents in the shrub-dominated community. Based on a linear regression model, soil infiltration rate (IN) could be predicted by silt content (SL) and clay content (CL): IN=37.87-0.315SL-0.527CL (Hajiaghaei et al., 2014). It should be noted that instant infiltration rate in the three sites would be underestimated when the rainfall amount was extremely high (e.g., 68.0 and $146.0 \mathrm{~mm}$ ).

\subsection{Penetration depth}

Small rainfall events can only cause minor fluctuations in surface soil moisture and major portion of the rainfall can be directly lost as soil evaporation (Heisler-White et al., 2008). It was reported that only rainfall events that exceed $2.0 \mathrm{~mm}$ can cause physiological responses in plants (Sala and Lauenroth, 1982; He et al., 2012) and that a single large rainfall event or two consecutively-occurred moderate rainfall events could bring about major fluctuations of soil water in deeper layer (i.e., 60-80 cm) in arid and semi-arid regions (He et al., 2012). Our study 
shows that the replenishment of soil water in deeper layers was mainly resulted from the accumulation of several rainfall events or one large event. Our study also shows that the rainfall events larger than $30.0 \mathrm{~mm}$ still failed to replenish the soil water in deeper soil layer $(60-80 \mathrm{~cm})$ under the herb-dominated community. The failure to replenish deeper-layer soil water under the herb-dominated community may be resulted from the changes in hydraulic conductivity. The changes in hydraulic conductivity was associated with the changes in soil texture and the latter (soil-texture changes) was brought about by the vegetation succession from the shifting dune (no vegetation), through the shrub-dominated community, to the herb-dominated community (Wilcox et al., 2003; Li et al., 2008).

Previous studies concluded that hydraulic conductivity in soil was controlled by the porosity and continuity of macro pores (Lebron et al., 2007; Zhang et al., 2013). With the A. ordosica community (i.e., the shrub-dominated community) established on the shifting dune, there were no significant changes in soil texture (i.e., no increases in silt and clay contents). But, at the higher stage of succession in the A. ordosica community (i.e., the herb-dominated community), silt and clay contents increased in the shallower layer (i.e., 0-20 cm), effectively impeding penetration of infiltrated water into deeper soil layers. Thus, rainfall penetration depth in the herb-dominated community was much shallower than those of the shifting dune and shrub-dominated community. Due to fact that most rainfall events in arid and semi-arid regions were less than $5.0 \mathrm{~mm}$ (Sala et al., 1982; Li et al., 2013), the soil water content in the deeper layer (i.e., 60-80 cm) is thus destined to being lower under the herb-dominated community.

Soil organic matter can be another factor contributing to the failure for relatively large rainfall events to replenish deeper-layer soil water under the herb-dominated community. Soil water holding capacity has been found to exhibit a strong positive correlation with organic matter content (Hudson, 1994; Konwar, 2016). Compared with the shrub-dominated community, soil in the herb-dominated community was able to store more water in shallower layers simply due to a higher water-holding capacity. The higher water-holding capacity in the herb-dominated community was simply resulted from a higher content of organic matter. That is, the organic matter-enriched shallower layer in the herb-dominated community allowed the water stay in the shallower layer and prevented the water from penetrating to the deeper layer.

\section{Conclusions}

This study presented continuous measurements of soil water content with 10-min time resolution at three sites: a shifting dune, a shrub-dominated community, and an herb-dominated community. The aim was to understand the ecohydrological responses to vegetation restoration in the Mu Us Sandy Land, Inner Mongolia of China. Our results show that soil water content was strongly affected by rainfall infiltration and surface characteristics. Infiltration coefficient increased with increased rainfall amount and eventually reached a stable value. Infiltration coefficient were approximately $0.91,0.64$, and 0.74 in the shifting dune, in the shrub-dominated community, and in the herb-dominated community, respectively. Cumulative infiltration and soil texture are two factors that affect rainfall penetration depth in significant ways. Only rainfall events larger than $35.0 \mathrm{~mm}$ could recharge soil water at the $60-80 \mathrm{~cm}$ layer in the herb-dominated community. Our results lend supports to the notion that vegetation succession after man-initiated vegetation restoration plays a critical role in soil water infiltration in arid and semi-arid areas. However, our results also imply that the expected forward succession of restored vegetation may be destined to deterioration after reaching the climax simply because of following two facts: (1) soil water is mainly retained in the shallower layer, and (2) plant fine roots mainly distribute in the deeper layer.

\section{Acknowledgements}

This work was supported by the National Natural Science Foundation of China (41130640, 41321001, 31470402), the Program for Changjiang Scholars and Innovative Research Team in University (IRT1108), and the Fundamental Research Funds for the Central Universities (2012CXQT07). 


\section{References}

Angelaki A, Sakellariou-Makrantonaki M, Tzimopoulos C. 2013. Theoretical and experimental research of cumulative infiltration. Transport in Porous Media, 100(2): 247-257.

Carlyle-Moses D E. 2004. Throughfall, stemflow, and canopy interception loss fluxes in a semi-arid Sierra Madre Oriental matorral community. Journal of Arid Environments, 58(2): 181-202.

Castellano M J, Valone T J. 2007. Livestock, soil compaction and water infiltration rate: evaluating a potential desertification recovery mechanism. Journal of Arid Environments, 71(1): 97-108.

Cheng X L, An S Q, Li B, et al. 2006. Summer rain pulse size and rainwater uptake by three dominant desert plants in a desertified grassland ecosystem in northwestern China. Plant Ecology, 184(1): 1-12.

Cobos D R, Chambers C. 2010. Calibrating $\mathrm{ECH}_{2} \mathrm{O}$ Soil Moisture Sensors, Application Note. Pullman, USA: Decagon Devices Inc., $1-7$.

Guo K. 2000. Cyclic succession of Artemisia ordosica Krasch. community in the Mu Us Sandy grassland. Acta Phytoecologica Sinica, 24(2): 243-247. (in Chinese)

Hajiaghaei A, Rashidi M, Sadeghi M A, et al. 2014. Prediction of soil infiltration rate based on silt and clay content of soil. American-Euransian Journal of Agricultural \& Environmental Science, 14(8): 702-706.

He Z B, Zhao W Z, Liu H, et al. 2012. The response of soil moisture to rainfall event size in subalpine grassland and meadows in a semi-arid mountain range: a case study in northwestern China's Qilian Mountains. Journal of Hydrology, 420-421: $183-190$

Heisler-White J L, Knapp A K, Kelly E F. 2008. Increasing precipitation event size increases aboveground net primary productivity in a semi-arid grassland. Oecologia, 158(1): 129-140.

HilleRisLambers R, Rietkerk M, van den Bosch F, et al. 2001. Vegetation pattern formation in semi-arid grazing systems. Ecology, 82(1): 50-61.

Hudson B D. 1994. Soil organic matter and available water capacity. Journal of Soil and Water Conservation, 49(2): 189-194.

Jeddi K, Chaieb M. 2010. Changes in soil properties and vegetation following livestock grazing exclusion in degraded arid environments of South Tunisia. Flora-Morphology, Distribution, Functional Ecology of Plants, 205(3): 184-189.

Konwar J. 2016. Soil texture and total organic matter content and its influences on soil water holding capacity of Municipality soils of Moran in Sivasagar district of Assam, India. International Journal of Scientific Research, 5(1): 536-537.

Lebron I, Madsen M D, Chandler D G, et al. 2007. Ecohydrological controls on soil moisture and hydraulic conductivity within a pinyon-juniper woodland. Water Resources Research, 43(8): W08422, doi: 10.1029/2006WR005398.

Li X J, Li X R, Song W M, et al. 2008. Effects of crust and shrub patches on runoff, sedimentation, and related nutrient (C, N) redistribution in the desertified steppe zone of the Tengger Desert, Northern China. Geomorphology, 96(1-2): 221-232.

Li X R, Ma F Y, Xiao H L, et al. 2004. Long-term effects of revegetation on soil water content of sand dunes in arid region of Northern China. Journal of Arid Environments, 57(1): 1-16.

Li X R. 2005. Influence of variation of soil spatial heterogeneity on vegetation restoration. Science in China Series D: Earth Sciences, 48(1): 2020-2031.

Li X R, Kong D S, Tan H J, et al. 2007. Changes in soil and vegetation following stabilisation of dunes in the southeastern fringe of the Tengger Desert, China. Plant and Soil, 300(1-2): 221-231.

Li X R, Zhang Z S, Huang L, et al. 2013. Review of the ecohydrological processes and feedback mechanisms controlling sand-binding vegetation systems in sandy desert regions of China. Chinese Science Bulletin, 58(13): 1483-1496.

Li X Y, Zhang S Y, Peng H Y, et al. 2013. Soil water and temperature dynamics in shrub-encroached grasslands and climatic implications: results from Inner Mongolia Steppe ecosystem of north China. Agricultural and Forest Meteorology, 171-172: $20-30$.

Liu G S. 1996. Soil Physical and Chemical Analysis \& Description of Soil Profiles. Beijing: Standards Press of China, 38-39. (in Chinese)

Liu N, Zhou L H, Chen Y, et al. 2014. Identification and evaluation of desertification reversal in China: indicators and methods review. Sciences in Cold and Arid Regions, 6(3): 190-200.

Liu S G. 1997. A new model for the prediction of rainfall interception in forest canopies. Ecological Modelling, 99(2-3): $151-159$.

Millennium Ecosystem Assessment. 2005. Ecosystems and Human Well-Being: Desertification Synthesis. Washington D.C.: World Resource Institute: 18-20.

Rietkerk M, van de Koppel J. 1997. Alternate stable states and threshold effects in semi-arid grazing systems. Oikos, 79(1): 69-76. 
Sala O E, Lauenroth W K. 1982. Small rainfall events: an ecological role in semiarid regions. Oecologia, 53(3): 301-304.

Su Y Z, Li Y L, Cui J Y, et al. 2005. Influences of continuous grazing and livestock exclusion on soil properties in a degraded sandy grassland, Inner Mongolia, northern China. Catena, 59(3): 267-278.

van de Koppel J, Rietkerk M, Weissing F J. 1997. Catastrophic vegetation shifts and soil degradation in terrestrial grazing systems. Trends in Ecology \& Evolution, 12(9): 352-356.

van de Koppel J, RietkerK M, van Langevelde F, et al. 2002. Spatial heterogeneity and irreversible vegetation change in semiarid grazing systems. The American Naturalist, 159(2): 209-218.

van de Koppel J, Rietkerk M. 2004. Spatial interactions and resilience in arid ecosystems. The American Naturalist, 163(1): 113-121.

Walkley A, Black I A. 1934. An examination of the Degtjareff method for determining soil organic matter, and a proposed modification of the chromic acid titration method. Soil Science, 37(1): 29-38.

Wang Q S, Dong X J, Chen X D, et al. 1997. Study on some features of Artemisia ordosica community at the different successional stages. Acta Phytoecologica Sinica, 21(6): 531-538. (in Chinese)

Wang S, Fu B J, Gao G Y, et al. 2013. Responses of soil moisture in different land cover types to rainfall events in a re-vegetation catchment area of the Loess Plateau, China. Catena, 101: 122-128.

Wang T, Wu W, Xue X, et al. 2004. Spatial-temporal changes of sandy desertified land during last 5 decades in northern China. Acta Geographica Sinica, 59(2): 203-212. (in Chinese)

Wang X P, Li X R, Kang E S, et al. 2003. The infiltration and redistribution of precipitation in revegetated sand dunes in the Tengger Desert, Shapotou, China. Acta Ecologica Sinica, 23(6): 1234-1241. (in Chinese)

Wang X P, Kang E S, Zhang J G, et al. 2004. Comparison of interception loss in shrubby and sub-shrubby communities in the Tengger desert of northwest China. Journal of Glaciology and Geocryology, 26(1): 89-94. (in Chinese)

Wang X P, Li X R, Xiao H L, et al. 2007. Effects of surface characteristics on infiltration patterns in an arid shrub desert. Hydrological Processes, 21(1): 72-79.

Wang X P, Zhang Y F, Hu R, et al. 2012. Canopy storage capacity of xerophytic shrubs in Northwestern China. Journal of Hydrology, 454-455: 152-159.

Wilcox B P, Breshears D D, Turin H J. 2003. Hydraulic conductivity in a Piñon-juniper woodland. Soil Science Society of America Journal, 67(4): 1243-1249.

Yang X, Zhang K, Jia B, et al. 2005. Desertification assessment in China: an overview. Journal of Arid Environments, 63(2): 517-531.

Zhang H J, Wu B, Yang W B, et al. 2012. Soil moisture characteristics of Artemisia ordosica community at different succession stages in Mu Us Sandy Land. Journal of Desert Research, 32(6): 1597-1603. (in Chinese)

Zhang X S. 1994. Principles and optimal models for development of Maowusu Sandy grassland. Acta Phytoecologica Sinica, 18(1): 1-16. (in Chinese)

Zhang Z H, Li X Y, Jiang Z Y, et al. 2013. Changes in some soil properties induced by re-conversion of cropland into grassland in the semiarid steppe zone of Inner Mongolia, China. Plant and Soil, 373(1): 89-106. 